\title{
Asyluxu Gotes.
}

DIFFICULTIES WHICH PREVENT THE REALIZATIQ̣N OF DR. MITCHELL'S IDEAL HOSPITAL FOR THE INSANE.

\section{BY LIVINGSTON S. HINCKLEY,}

Essex County Hospital for the Insane, Newark, N. J,

In an address before the fifteenth annual meeting of the American Medico-psychological Association, held in Philadelphia, May 16, I894, Dr. Weir.Mitchell sounded an alarm which should rouse alienists and asylum superintendents throughout the country, force them to assume an attitude of defense, if they have any to make, or compel them to acknowledge the justice of a terrible condemnation.

When Dr. Mitchell, whose statements are strongly supported by such eminent American authorities as Billings, Dana, Draper, Folsom, Gray, Hamilton, Loomis, Hammond, Lyman, Star, Osler, Wood, Zenner and Spitzka, boldly reproaches individually and collectively all of our medical superintendents for their sins of omission and of commission, and declares them unworthy of the dignity and honor of a title whose escutcheon they have sullied; when he denounces in scathing. terms the whole vast system of asylum management for which they are responsible, and intimates that they have lapsed into a state of professional apathy; when he publishes to the world that they have not only failed to keep abreast with the great strides made in all other branches of medical science, but that in many instances incompetency, indifference, personal greed and the "sclerosis of customs have rendered asylums no better than huge boarding houses" bunglingly kept by pompous individuals who bear the " absurd title of medical superintendents," it is high time for these gentlemen to rise either " to a point of order" or to explain.

In this short paper an elaborate review of Dr. Mitchell's long and able address is obviously impossible. At the risk of being misunderstood on account of the 
brevity and fragmentary nature of these cursory remarks, the writer desires to point out certain facts and conditions incident to the present system of asylum keeping which seem to have escaped Dr. Mitchell's critical eye, and to examine, briefly of course, his proposed system of therapeutics for the insane.

The experience of several years in asylum work and frequent attrition with superintendents of both State and county asylums, when grievances have been freely discussed and troubles incident to administration laid bare, have developed the opinion that the present system of asylum management is a monstrous fallacy--a fact that no candid mind informed upon this subject can gainsay.

Far be it from the intention of this pen to convey the idea that advantage has been taken of the time, place, and opportunity to parade a personal skeleton from its closet; but ignoring local conditions in consideration of the introspection of universal shortcomings, attributed, and, in fact, easily traced to the sole obstruction to rapid and progressive evolution.

Indeed, it would presage the assumption of an exceeding lack of gratitude to attack through this paper the present board of managers of the institution from which this paper emanates, from the fact that the liberal and progressive views of that body have marked a pro. nounced step in the advance of the evolution we strive for, but which is yet conspicuous by its incompleteness. Appointed and sustained in office by a board of politicians as he is, the superintendent finds himself embarrassed and handicapped by the same political policies of those who tolerate him at all, and instead of devoting his whole time and energies to the upbuilding of a really scientific institution he discovers that he frequently has his hands full to appease the demands, humor the whims and satisfy the wishes of each member of an autocratic board. It is not astonishing that such officious intermeddling is often a most exasperating source of annoy. ance to the medical superintendent.

It is inconceivable that a member of a board of general managers could be so inconsiderate and arbitrary as to force the superintendent of an asylum to allow a patient to be seen by friends when such a procedure is considered therapeutically contra-indicated and detrimental to the interest and welfare of the patient so disturbed. Yet such pernicious interposition is a recorded fact. If the bedside of patients does not escape the 
grasp of political interference, what indescribable havoc must often be created in those departments less intimately connected with the medical work!

Attendants or other employees suspended or discharged by the superintendent for wilful breach of discipline, defiance of the authority of superior officers, or culpable neglect of duty, have in several instances been promptly reinstated by boards of managers for political reasons only: Trained and competent nurses have been hounded out of their positions to make room for those who have a "pull." The entire corps of employes, from steward to cook, is changed to suit the political complexion of the reigning board. Positions of grave responsibility are filled by employees whose stupidity, illiteracy, and total lack of adaptability, are painfully apparent. The expenditure of a few dollars to meet the bare exigencies of minor surgery and lesser gynæcology is grudgingly allowed, while the mere consideration of the propriety of purchasing elaborate modern appàratus for mechano,- electro- and hydro-therapy, although strongly recommended by medical superintendents, is flatly refused. The gross misconception of the true principles of economy, and the fatal method of forcing down legitimate expenses in order to show an actual saving of dollars and cents which is too often the policy adopted by the managers of our institutions of charity throughout the land, are fraught with the most baneful consequences. It is not the absolute amount expended that shows the wisdom or incompetency of a financial board; it is how that amount is used, whether to pay high wages to useless employes, or to promote the comfort and improve the treatment of the unfortunate inmates.

Even the training schools for nurses which a linited number of asylum superintendents have worked so.faithfully to establish, do not always escape the jealous slur of selfishness. Some boards have fought the schools openly, others have stabbed them in secret, and a few have encouraged the enterprise either officially or personally in a quiet way.

So much for the part played by these political influences in one of America's greatest systems of charities No, Dr. Mitchell, it is not " all mere scandalous gossip." It is "ward politics at the bedside of the lunatic!" But it is one thing to see that a line is crooked, and quite another to be able to draw a straight one.

In view of the demoralizing consequences which the 
interference of frequently. changing partisan boards of managers entail, consequences fraught with perplexing difficulties that almost daily confront the superintendents of a vast majority of public asylums in America, and recognizing how futile have been their efforts to emancipate their work from the manacles of political power, it is clear to the mind of an impartial observer that in his sharp criticism and wholesale condemnation of medical superintendents, Dr. Mitchell has been unjustly severe.

It is true that our.alien literature and asylum reports are too painfully barren of original research in the pathology and therapeutics of insanity. But are medical superintendents solely responsible for this scientific unproductiveness? Do your medical colleges do their whole duty in training young men in the fundamental principles of psychology and neuro-pathology? Do they emphasize the importance of this branch of study with such force and energy in lectures, clinics and quizzes as they do general medicine, surgery, gynæcology and neurology? In most all of our colleges little or no attention is given to the subject of insanity. To the chair of "nervous diseases" is incidentally appended a few cursory lectures on insanity. These lectures are almost invariably delivered in empty halls to vacant seats; for the lecturer manifests so little interest and enthusiasm in the subject of his discourses that students are impressed with the belief that such lectures are only thrown in to fill up space and are wholly irrelevant. In the final college examination, questions on mental diseases are exceedingly rare. No great pathologists are devoting their sole time to the microscopic study of the morbid conditions of nerve structure in its relation to insanity.

Indeed, insanity is a vast unexplored continent, a faint knowledge of whose shores suggest untold wealth of scientific information ready to reward those who patiently and courageously penetrate its mysterious interior; for, to use the words of a great writer, "in the brain, that wondrous world with one inhabitant, there are recesses dim and dark, treacherous sands and dangerous shores, where seeming sirens tempt and fade, streams that rise in unknown lands from hidden springs, strange seas with ebb and flow of tides, restless billows urged by storms of flame; profound and awful depths hidden by mist of dreams, obscure and phantom realms where 
vague and fearful things are half revealed; jungles where passions' tigers crouch, and skies of cloud and blue where fancies fly with painted wings to dazzle and mislead; and the lone wanderer in this pictured world, enwrapped by the emotions of an exuberant soul, wends his way across green fields and blooming meadows, beside cooling springs, sparkling cascades and shady groves, or he is led by old desires, and ancient hates, and stained by crimes of many vanished years, and pushed by hands that long ago were dust, until he becoms a bewildered slave that mockery has throned and crowned"-the delight of insanity, the pain of madness.

In this limitlesss and fascinating field of scientific research many ambitious and able young men could be easily induced to make a life study, if colleges. would rouse them to a sense of its importance and asylum authorities would encourage and stimulate them by paying better salaries and fitting up laboratories for such work.

The assistant physicians do the most of the special and individual professional work in asylums, and, receiving as they do mere pittance of salaries, it is impossible to secure the services of the most talented and best equipped young physicians.

Dr. Mitchell bewails the " amazing lack of complete physical study of the insane, the oddly defective schedule guide to symptom notes, the failure to see obvious lesions, the want of thorough day by day study of the secretions in the newer cases, of blood-counts, temperatures, reflexes, eye-ground, color fields," and to cap the climax of his indignation, he accuses asylum superintendents of fostering the superstition and "wide-spread belief that there is some mysterious therapeutic in: fluence to be found behind the grim walls and locked doors of asylums for the insane."

These grave charges cannot be ignored. Such an unqualified arraignment, frowning down with such unwonted severity upon this great body of American alien. ists, is extremely unjust, and, if not refuted or explained, fraught with most disastrous consequences to the public confidence imposed in these gentlemen. His high professional repute, his unimpeachable integrity and the earnest fervor of his noble life work, bear overwhelming testimony to 'Dr. Mitchell's sincerity of motive and honesty of purpose. But to the thoughtful student of 
insanity, who has had sufficient practical experience in its treatment in any of our large public asylums to enable him to separate the useful and practicable remedies at our disposal from the great mass of therapeutic fiction with which Utopian dreamers have burdened our literature, Dr. Mitchell's ideal hospital for the insane, his romantic therapeutics and his corps of trained nurses, whose psychic influence enables them to sway the feelings and control the impulses of maniacs as easily as did the legendary saints of old, savors of the highly-colored visions of a traveller in Altruria, rather than of the careful, accurate suggestions of a scientist whose judgment had been moulded by the experience of many years. Most assuredly the minute details of thorough physical examinations of all cases of insanity would not only be of vast. interest to scientists, but would serve as invalu. able guides to rational treatment. The profession will owe a lasting debt of gratitude to the clinician who will present a method for successfully testing the eye-ground and color-field of patients who, by reason of their mental condition, are unable to distinguish between a man and an ox. In a large majority of insane patients a satisfactory ophthalmoscopical examination is absolutely impossible. In his efforts to take the temperature of violent patients, the physician of great tact and ingenuity often fails completely. The stethoscope is useless in many cases, unless narcosis or anæthesia be produced, which procedure necessarily alters the character of, and ratio between, respiration and circulation.

That mechanical restraint which merely checks the outward muscular movements while motor energy is all the while being generated in the brain convolutions, is eminently unphysiological, cannot be questioned. Would it be wiser to allow this morbid storm of motor energy to seek the path of least resistance by permitting the patient to walk, and run, and dig, and push a wheelbarrow until his muscles become tired out? Would not such a mode of procedure entail an additional complication, namely, physical exhaustion, depression of all the vital functions of the body, impaired digestion and rapid tissue starvation?

Would not a violent and destructive maniac upset the serene tranquillity of Dr. Mitchell's ideal asylum by tearing to pieces his flower-beds, shattering his painted vases, breaking: his bicycles, and using the croquet balls and mallets to disturb the comfort, molest the peace and 
endanger the personal safety of fellow patients? To keep one strong, muscular patient, with destructive tendencies, out of mischief, it would require the constant vigilance of at least one trustworthy attendant and the united strength of several. Occasionally a patient who is not dangerously violent, is persistently denuding, tearing his clothing into shreds, and resorting to petty self-mutilations, such as picking his nose, eyes and ears until they become inflamed and sore. Such patients are often oblivious to all external impressions, every movement being an unconscious reflex act. Would not a light form of mechanical restraint, such as neat canvas muffs applied to the hands so as to prevent the use of the fingers, be preferable to the monoplizing of the en. tire time of one or more nurses who would be compelled to use manual restraint which would confine the movements of the whole arm instead of the fingers only, and which would be an additional source of irritation to the patient?

In the violent wards of our public asylums, where there are fifteen patients to one attendant, it is clearly evident that some sort of restraint becomes at times ab. solutely unavoidable. It is a condition and not a theory that confronts a physician of such a ward. The only question involved is whether the restraint shall be of a mechanical or chemical nature. Disturbing as it does the physiological equilibrium of the whole body, checking secretion and excretion, interfering with digestion and arresting both constructive and destructing meta. bolism. That treatment which requires the continuous use of powerful drugs to stun and narcotize the central nerve centres is not only highly reprehensible practice, but is productive of most disastrous consequences to the patient.

The writer is constrained to believe that the mortality is lower in those institutions where the potential principles of non-restraint are sacrificed for the benefit of the patient. The introduction of a system of treatment which would enable alienists to treat successfully all cases of insanity without resorting to any form of restraint, either chemical or mechanical, would mark an epoch in the history of psychic therapeutics, and would be regarded as the greatest triumph of modern medicine.

In his extravagant notions of an ideal asylum, and in his extraordinary faith in the efficacy of moral suasion 
in controlling the insane mind, Dr. Mitchell ignores the fundamental nature of mental aberation. The impulsive thoughts of an insane person which tend to deeds of violence, homicide or suicide, are as truly pathological and beyond the controi of the will as are the psychical convulsions which mark the fatal culmination of these morbid ideas. An insane being can no more resist an inclination to destroy flower vases, paintings or statuary because they are beautiful, or keep from striking an attendant because he is conscious that he possesses the latter's friendship, than he can control the movements of chorea because he is in company, or stop the spasms of strychine poison because he knows the physiological action of the drug.

Of course, there are many forms of insanity as well as many degrees of intensity in any given form, so that by a careful selection of cases suited to his ideal asylum, where restraint is unknown, where the gates stand wide ajar and doors have no locks, where flowers and music and art heal the diseased brain, where nurses trained in the clairvoyance of psychic influence soothe the morbid fears, sweeten the bitter thoughts and subdue the wild delirium of a tortured mind, where the physician's magic "peace be still" calms the tempestuous sea of insane passions and turns the blackness of demented despair into the light of healthful cheer, it is possible for Dr. Mitchell to realize a consummation of his great hope. although he admits that science will not reach such ideal perfection in his day.

In conclusion, it is scarcely necessary for the writer to intimate that the present lack of knowledge touching the anatomical situation and pathological nature of the lesions which induce insanity, preclude the possibility of basing our therapeutics upon a highly scientific rationale; for alienists confess that, so far as the real nature of mental diseases is concerned, they must agree with Sir William Hamilton that "the highest reach of human science is but the scientific recognition of human ignorance." Let us hope that, although the vague theories of speculative philosophy have obscured the horizon of psychology, the marvelous light of experimental science will ere long lift the entire system of caring for the insane to a higher plane of humane and scientific therapy.

In the meantime, let us make haste slowly, for science does not advance by the spasmodic leaps of revolution, but by the sturdy sure march of evolution. 